\title{
Acute kidney injury in postoperative shock: is hyperoncotic albumin administration an unrecognized resuscitation risk factor?
}

\author{
Chiedozie I. Udeh ${ }^{1 *} \mathbb{D}$, Jing You², Matthew R. Wanek ${ }^{3}$, Jarrod Dalton ${ }^{4}$, Belinda L. Udeh ${ }^{4,5}$, Sevag Demirjian ${ }^{6}$, \\ Nadeem Rahman ${ }^{7}$ and J. Steven Hata ${ }^{1}$
}

\begin{abstract}
Background: The use of hyperoncotic albumin (HA) for shock resuscitation is controversial given concerns about its cost, effectiveness, and potential for nephrotoxicity. We evaluated the association between early exposure to hyperoncotic albumin (within the first $48 \mathrm{~h}$ of onset of shock) and acute organ dysfunction in post-surgical patients with shock.

Methods: This retrospective, cohort study included 11,512 perioperative patients with shock from 2009 to 2012. Shock was defined as requirement for vasopressors to maintain adequate mean arterial pressure and/or elevated lactate (> $2.2 \mathrm{mmol} / \mathrm{L})$. Subsets of 3600 were selected after propensity score and exact matching on demographics, comorbidities, and treatment variables ( $>30)$. There was a preponderance of cardiac surgery patients. Proportional odds logistic regression, multivariable logistic regression or Cox proportional hazard regression models measured association between hyperoncotic albumin and acute kidney injury (AKI), hepatic injury, ICU days, and mortality.

Results: Hyperoncotic albumin-exposed patients showed greater risk of acute kidney injury compared to controls (OR 1.10, 95\% Cl 1.04, 1.17. $P=0.002$ ), after adjusting for imbalanced co-variables. Within matched patients, 20.3\%, $2.9 \%$, and $4.4 \%$ of HA patients experienced KDIGO stages $1-3 \mathrm{AKl}$, versus $19.6 \%, 2.5 \%$, and $3.0 \%$ of controls. There was no difference in hepatic injury (OR 1.16; 98.3\% Cl 0.85, 1.58); ICU days, (HR 1.05; 98.3\% Cl 1.00, 1.11); or mortality, (OR 0.88; 98.3\% Cl 0.64, 1.20).

Conclusions: Early exposure to hyperoncotic albumin in postoperative shock appeared to be associated with acute kidney injury. There did not appear to be any association with hepatic injury, mortality, or ICU days. The clinical and economic implications of this finding warrant further investigation.
\end{abstract}

Keywords: (National Library of Medicine-Medical Subject Headings): Albumin, Resuscitation, Acute kidney injury, Shock, Multiple organ failure

\section{Background}

Resuscitation with administration of hyperoncotic albumin is controversial with regard to clinical outcomes and organ injury in shock. Hyperoncotic colloids exert higher osmotic pressure relative to human plasma, a characteristic exponentially and directly related to the colloid concentration. Thus, 5\% albumin with a colloid osmotic pressure similar to plasma is isooncotic.

\footnotetext{
* Correspondence: udehc@ccf.org

${ }^{1}$ Center for Critical Medicine, Anesthesiology Institute, 9500 Euclid Avenue, (J4-331), Cleveland, OH 44195, USA

Full list of author information is available at the end of the article
}

Whereas 20\% albumin with osmotic pressure nearly 8 -fold higher than plasma is classified as hyperoncotic, as are hydroxyethyl starch solutions at $6 \%$ or greater (Hiippala et al. 1991; Tonnessen et al. 1993). Owing to this characteristic, hyperoncotic fluids have been used for resuscitation. Proponents contend that albumin could limit organ damage in shock states, by achieving hemodynamic goals with smaller fluid volumes and avoiding adverse consequences of hypervolemia.

The use of $25 \%$ albumin is partly based on the presumption that distribution of administered albumin is primarily intravascular. If so, albumin should raise colloid oncotic

(c) The Author(s). 2018 Open Access This article is distributed under the terms of the Creative Commons Attribution 4.0 International License (http://creativecommons.org/licenses/by/4.0/), which permits unrestricted use, distribution, and 
pressure and expand plasma volume in shock. However, evolving understanding of endothelial glycocalyx physiology has upended the classic Starling principles of transendothelial fluid and protein flux (Woodcock and Woodcock 2012; Chappell et al. 2008; Levick and Michel 2010; Becker et al. 2010). It is now established that the kinetics of albumin differ markedly between health and critical illness states; such that the normal trans-capillary escape rate of albumin increases 100-300\% in shock states due to increased permeability (Nicholson et al. 2000). Consequently, the effectiveness of resuscitation with hyperoncotic albumin has been questioned. Clinically, this is underscored by the fact that when compared to less costly crystalloids, hyperoncotic albumin solutions have not conferred mortality or other outcome benefits in shock (Myburgh 2008; Roch et al. 2011; Polito and Martin 2013; Raghunathan et al. 2015; Schortgen et al. 2010). Indeed, outcomes and adverse effects of hyperoncotic albumin, other colloids, and crystalloids in acute resuscitation have been found to be similar (Finfer et al. 2004; Bunn and Trivedi 2012; Patel et al. 2014; Jiang et al. 2014; Stockwell et al. 1992a; Stockwell et al. 1992b).

Additionally, concerns have been raised periodically about this paucity of benefit, yet possible harm from hyperoncotic colloids, including potential nephrotoxicity and mortality (Brochard et al. 2010; Hartog et al. 2011; Perel et al. 2013; Zarychanski et al. 2013; Moran and Kapsner 1987). These culminated in systematic reviews and prompted consensus recommendations against continued use of hetastarches due to nephrotoxicity. As a result, hyperoncotic albumin may be the sole colloid in many hospitals (Brochard et al. 2010; Hartog et al. 2011; Perel et al. 2013; Zarychanski et al. 2013). However, other observational cohort studies of resuscitation have suggested increased risks of acute kidney injury (AKI) associated with hyperoncotic albumin in shock (Frenette et al. 2014; Schortgen et al. 2008). It is therefore crucial to clarify any renal impact of hyperoncotic albumin administration during the high-risk period of shock. Accordingly, the goal of this study was to evaluate the association between early exposure to hyperoncotic albumin (within the first $48 \mathrm{~h}$ of onset of shock) and acute organ dysfunction in postsurgical patients with shock.

\section{Methods}

The Cleveland Clinic Institution Review Board approved this study and waived informed consent. The design was a retrospective, propensity score-matched cohort study with pre-specified analyses (Schuhlen 2014). The study sample included surgical patients ( $>18$ years) admitted to the surgical intensive care unit or the cardiovascular surgical intensive care unit at Cleveland Clinic from 2009 to 2012 with shock. Eligible patients were identified from institutional electronic medical records (Epic Systems
Corporation $\odot$, Verona, WI, USA). Patients with missing data for renal function or vital status were excluded. Patient selection required an admission to the ICU with elevated serum lactate level $>2.2 \mathrm{mmol}$ or administration of vasopressors within the first $12 \mathrm{~h}$ of ICU stay.

Consistent with recent consensus definitions for septic shock, shock was defined as requirement for vasopressors to maintain adequate mean arterial pressure and/or elevated lactate (Shankar-Hari et al. 2016). The cut-off threshold for lactate was $2.2 \mathrm{~mol} / \mathrm{L}$, reflecting the upper end of the reference range for serum lactate at the Cleveland Clinic clinical laboratory. In order to assess the impact of early exposure to hyperoncotic albumin, we identified patients who received $25 \%$ albumin during the first $48 \mathrm{~h}$ of resuscitation for shock. Flexbumin 25\% * (Baxter Healthcare Corp, Westlake Village, CA, USA), a $12.5 \mathrm{~g}, 50 \mathrm{ml}$ solution, is the only formulation of hyperoncotic albumin used in the intensive care units at Cleveland Clinic.

The primary outcome was risk of acute kidney injury (AKI), defined by serum creatinine changes as per the Kidney Disease Improving Global Outcomes (KDIGO) criteria (Khwaja 2012). The KDIGO definition of acute kidney injury includes the following: stage 1: serum creatinine with a 1.5 to 1.9 times baseline or $\geq 0.3 \mathrm{mg} / \mathrm{dl}$ $(\geq 26.5 \mu \mathrm{mol} / \mathrm{l})$ increase; stage 2 : serum creatinine 2.0 to 2.9 times baseline. Stage 3: serum creatinine of 3.0 times baseline or increase in serum creatinine to $\geq 4.0 \mathrm{mg} / \mathrm{dL}$ $(\geq 353.6 \mu \mathrm{mol} / \mathrm{L})$ or initiation of renal replacement therapy. Secondary outcomes included in-hospital mortality, duration of ICU stay, and risk of liver injury. Using a threshold for more severe dysfunction in the liver component of the SOFA score, hepatic injury was defined as total bilirubin $>6.0 \mathrm{mg} / \mathrm{dl}$ (Vincent et al. 1996).

\section{Statistical analysis}

SAS software version 9.3 (SAS Institute, Cary, NC, USA) was used for statistical analysis. Sample size estimation was based on the CRYCO study which had overall incidence of acute renal events of 17\% (Schortgen et al. 2008). In that study, acute renal events occurred in 10\% and 35\% of crystalloid and hyperoncotic albumin exposed patients, respectively. Similarly, renal injury after cardiac surgery has been reported with an incidence of $25 \%$ (Bastin et al. 2013). Based on these studies, assuming 20\%, $5 \%$, and $5 \%$ rates of stage 1-3 AKI respectively, 4000 subjects would be required for statistical power of 0.90 to detect an odds ratio of 0.8 for an ordinal outcome.

To control for confounders, propensity score and exact matching based on Elixhauser comorbidity measures, demographics, and treatment variables was performed to balance the albumin-exposed and non-exposed patients (Tables 1 and 2) (Elixhauser et al. 1998). During the period covered by our study, physiologic scoring indices for acuity were not consistently available in the study ICUs. 
Table 1 Demographic and perioperative characteristics of albumin-exposed and non-exposed patients before and after matching with respect to absolute standardized difference

\begin{tabular}{|c|c|c|c|c|c|c|}
\hline \multirow[t]{2}{*}{ Variable } & \multicolumn{3}{|l|}{ All patients } & \multicolumn{3}{|c|}{ Matched patients } \\
\hline & $\begin{array}{l}\text { Albumin } \\
(N=4669)\end{array}$ & $\begin{array}{l}\text { Control } \\
(N=6843)\end{array}$ & $\mathrm{ASD}^{*}$ & $\begin{array}{l}\text { Albumin } \\
(N=3600)\end{array}$ & $\begin{array}{l}\text { Control } \\
(N=3600)\end{array}$ & $\mathrm{ASD}^{*}$ \\
\hline Age, years & $67 \pm 13$ & $63 \pm 15$ & 0.238 & $66 \pm 13$ & $66 \pm 13$ & 0.015 \\
\hline Gender (male), no. (\%) & $2882(62)$ & $4203(61)$ & 0.006 & $2239(62)$ & $2269(63)$ & 0.017 \\
\hline Race & & & 0.087 & & & 0.018 \\
\hline Caucasian & $4197(90)$ & $6000(88)$ & & $3220(89)$ & $3239(90)$ & \\
\hline African American & $256(5)$ & $522(8)$ & & $198(6)$ & $185(5)$ & \\
\hline Others & $216(5)$ & $321(5)$ & & $182(5)$ & $176(5)$ & \\
\hline Body mass index, $\mathrm{kg} / \mathrm{m}^{2}$ & $28.4 \pm 6.5$ & $29.1 \pm 7.0$ & 0.108 & $28.6 \pm 6.3$ & $28.6 \pm 6.3$ & 0.014 \\
\hline ASA physical status, no. (\%) & & & 0.274 & & & 0.067 \\
\hline I & $18(0)$ & $46(1)$ & & $11(0)$ & $5(0)$ & \\
\hline$\|$ & $79(2)$ & $271(4)$ & & $51(1)$ & $45(1)$ & \\
\hline III & $985(21)$ & $2083(30)$ & & $755(21)$ & $672(19)$ & \\
\hline IV & $3587(77)$ & $4443(65)$ & & $2783(77)$ & $2878(80)$ & \\
\hline Emergent surgery, no. (\%) & $198(4)$ & $433(6)$ & 0.094 & $151(4)$ & $139(4)$ & 0.017 \\
\hline Type of surgery ${ }^{\dagger}$, no. (\%) & & & - & & & 0.000 \\
\hline Replacement of aortic valve & $1318(37.5)$ & $1495(37.3)$ & & $1120(37.3)$ & $1120(37.3)$ & \\
\hline CABG artery-vein single & $750(21.4)$ & $714(17.8)$ & & $621(20.7)$ & $621(20.7)$ & \\
\hline Replacement of mitral valve & $420(12.0)$ & $448(11.2)$ & & $391(13.0)$ & $391(13.0)$ & \\
\hline Repair of mitral valve & $343(9.8)$ & $411(10.3)$ & & $283(9.4)$ & $283(9.4)$ & \\
\hline Ascending aortic graft & $287(8.2)$ & $234(5.8)$ & & $225(7.5)$ & $225(7.5)$ & \\
\hline Revise ventricular muscle & $108(3.1)$ & $201(5.0)$ & & $96(3.2)$ & $96(3.2)$ & \\
\hline Transplantation of liver & $75(2.1)$ & $192(4.8)$ & & $73(2.4)$ & $73(2.4)$ & \\
\hline Exploration of abdomen & $100(2.9)$ & $133(3.3)$ & & 108 (3.6) & 108 (3.6) & \\
\hline Repair of mitral valve & $84(2.4)$ & $74(1.9)$ & & $61(2.0)$ & $61(2.0)$ & \\
\hline CABG arterial single & $27(0.8)$ & $106(2.6)$ & & $25(0.8)$ & $25(0.8)$ & \\
\hline Duration of surgery, (h) & $7.0 \pm 2.4$ & $6.5 \pm 2.6$ & 0.198 & $6.9 \pm 2.1$ & $6.8 \pm 2.1$ & 0.042 \\
\hline Intraoperative time-weighted average of $\mathrm{MAP}, \mathrm{mmHg}$ & $75.4 \pm 6.6$ & $77.4 \pm 8.3$ & 0.269 & $75.3 \pm 6.1$ & $75.1 \pm 6.3$ & 0.006 \\
\hline Use of hydroxyethyl starch, no. (\%) & $2326(50)$ & $3524(52)$ & 0.034 & $1854(52)$ & $2088(58)$ & 0.131 \\
\hline Use of furosemide, no. (\%) & $224(5)$ & $179(3)$ & 0.116 & $112(3)$ & $87(2)$ & 0.042 \\
\hline
\end{tabular}

ASA American Society of Anesthesiologist, ASD absolute standardized difference, MAP mean arterial blood pressure, TWA time-weighted average *ASD absolute difference in means or proportions divided by the pooled standard deviation; imbalance was defined as an ASD greater than 0.046 (i.e., $1.96 \times \sqrt{\frac{1}{3600}+\frac{1}{3600}}$ )

${ }^{\dagger}$ Ten most frequent procedures are listed

Also at that time, there was not yet institutional or national consensus on the use of hetastarch, which approximately $50 \%$ of our patients received. Accordingly, the American Society of Anesthesiologists (ASA) physical status classification, and exposure to hetastarch were included as variables for matching the cohorts. Vasopressors were included as single variable for the development of the model, because the clinical data were insufficient to differentiate effects on AKI risk among vasopressor types (Group. KDIGOKAKIW 2012).

We estimated each patient's probability of receiving albumin (their propensity score) using logistic regression with albumin as the outcome, and using all pre-specified potential confounders, except for type of surgery. We then 1-to-1 matched albumin-exposed and control patients using a greedy distance matching algorithm (SAS macro: gmatch) (Division of Biomedical Statistics and Informatics, Mayo Clinic (HSR CodeXchange) 2003). Successful matches were restricted to patients with the same type of surgery (by CPT code) and those whose logit function of the estimated propensity scores (i.e., $\log (\hat{p} /(1-\hat{p})$ estimated propensity score) were within 0.2 of the standard deviation of the logit of the propensity score (i.e., $0.2 \times 0.63=0.126$ ) of one another. Assessment of balance of the co-variables was 
Table 2 Comorbidities of albumin-exposed and non-exposed patients before and after matching with respect to absolute standardized difference

\begin{tabular}{|c|c|c|c|c|c|c|}
\hline \multirow[t]{2}{*}{ Comorbidity, no. (\%) } & \multicolumn{3}{|l|}{ All patients } & \multicolumn{3}{|l|}{ Matched patients } \\
\hline & Albumin $(N=4669)$ & Control $(N=6843)$ & $\mathrm{ASD}^{*}$ & Albumin $(N=3600)$ & Control $(N=3600)$ & $\mathrm{ASD}^{*}$ \\
\hline Congestive heart failure & $1985(43)$ & $1888(28)$ & 0.317 & $1397(39)$ & $1440(40)$ & 0.024 \\
\hline Vascular disease & $2509(54)$ & $2571(38)$ & 0.329 & $1924(53)$ & $1974(55)$ & 0.028 \\
\hline Pulmonary circulation disease & $454(10)$ & $457(7)$ & 0.111 & $293(8)$ & $294(8)$ & 0.001 \\
\hline Peripheral vascular disease & $970(21)$ & $1094(16)$ & 0.124 & $682(19)$ & $654(18)$ & 0.020 \\
\hline Hypertension, uncomplicated & $2960(63)$ & $3689(54)$ & 0.194 & $2232(62)$ & $2264(63)$ & 0.018 \\
\hline Hypertension, complicated & $41(1)$ & $91(1)$ & 0.043 & $35(1)$ & $41(1)$ & 0.017 \\
\hline Paralysis & $42(1)$ & $87(1)$ & 0.036 & $30(1)$ & $28(1)$ & 0.006 \\
\hline Chronic pulmonary disease & $780(17)$ & $910(13)$ & 0.096 & $548(15)$ & $555(15)$ & 0.006 \\
\hline Diabetes w/o chronic complications & $881(19)$ & $1152(17)$ & 0.053 & $671(19)$ & $673(19)$ & 0.001 \\
\hline Diabetes w/ chronic complications & $112(2)$ & $159(2)$ & 0.005 & $86(2)$ & $91(3)$ & 0.009 \\
\hline Hypothyroidism & $590(13)$ & $691(10)$ & 0.080 & $429(12)$ & $410(11)$ & 0.017 \\
\hline Renal failure & $517(11)$ & $615(9)$ & 0.069 & $374(10)$ & $362(10)$ & 0.011 \\
\hline Liver disease & $165(4)$ & $283(4)$ & 0.032 & $137(4)$ & $118(3)$ & 0.029 \\
\hline Peptic ulcer disease (non-bleeding) & $0(0)$ & $2(0)$ & 0.025 & $0(0)$ & $1(0)$ & 0.025 \\
\hline Lymphoma & $130(3)$ & $193(3)$ & 0.002 & $104(3)$ & $102(3)$ & 0.004 \\
\hline Metastatic cancer & $49(1)$ & $74(1)$ & 0.003 & $32(1)$ & $25(1)$ & 0.023 \\
\hline Solid tumor w/out metastasis & $451(10)$ & $637(9)$ & 0.012 & $324(9)$ & $317(9)$ & 0.007 \\
\hline Rheumatoid arthritis/collagen vas & $102(2)$ & $167(2)$ & 0.017 & $86(2)$ & $82(2)$ & 0.007 \\
\hline Coagulopathy & $1784(38)$ & $1570(23)$ & 0.336 & $1192(33)$ & $1145(32)$ & 0.028 \\
\hline Obesity & $234(5)$ & $341(5)$ & 0.001 & $169(5)$ & $186(5)$ & 0.022 \\
\hline Weight loss & $581(12)$ & $620(9)$ & 0.109 & $373(10)$ & $356(10)$ & 0.016 \\
\hline Fluid and electrolyte disorders & $3282(70)$ & $3873(57)$ & 0.287 & $2481(69)$ & $2546(71)$ & 0.039 \\
\hline Chronic blood loss anemia & $59(1)$ & $106(2)$ & 0.025 & $51(1)$ & $50(1)$ & 0.003 \\
\hline Deficiency anemias & $911(20)$ & $1184(17)$ & 0.057 & $685(19)$ & $686(19)$ & 0.001 \\
\hline Alcohol abuse & $84(2)$ & $123(2)$ & 0.000 & $61(2)$ & $75(2)$ & 0.029 \\
\hline Drug abuse & $27(1)$ & $58(1)$ & 0.032 & $22(1)$ & $16(0)$ & 0.024 \\
\hline Psychoses & $159(3)$ & $277(4)$ & 0.034 & $133(4)$ & $129(4)$ & 0.006 \\
\hline
\end{tabular}

${ }^{\bar{*}}$ ASD absolute difference in means or proportions divided by the pooled standard deviation; imbalance was defined as an ASD greater than 0.046 (i.e., $\left.1.96 \times \sqrt{\frac{1}{3600}+\frac{1}{3600}}\right)$

performed using absolute standardized differences (ASD), i.e., difference in means or proportions divided by the pooled standard deviation). Imbalance was defined as an absolute standardized difference $>0.046(1.96 \times \sqrt{ }(1 / 3600+$ $1 / 3600)$. Any imbalanced co-variables would be entered into the models comparing albumin and control patients on outcomes to reduce potential confounding.

We used proportional odds logistic regression model to assess the association between the exposure to albumin and AKI. This sort of model accounts for the ordinal nature of the response variable (i.e., "no AKI" better than "stage 1 AKI" better than "stage 2 AKI" better than "stage 3 AKI"). It yields an estimate of the relative odds of developing a more severe stage of AKI for albumin versus by control patients. These estimates are assumed to be proportional across the risk spectrum, i.e., the relative odds of AKI (of any stage) vs. no AKI are assumed to be equivalent to the relative odds of stage 2 or higher AKI vs. either no AKI or stage 1 AKI.

For the secondary outcomes, the cohorts were compared using multivariable logistic regression or Cox proportional hazard regression, as appropriate. We applied the Bonferroni correction to control for inflated type I error, thereby using a significance level of 0.017. The summary statistics were reported as mean \pm standard deviation for normally distributed continuous variables or median [firstthird quartiles] for non-normally distributed continuous variables or number (\%) for categorical variables, as appropriate. The normality was assessed by Shapiro-Wilk test. The statistical significance level was 0.05 . 


\section{Results}

We identified 25,025 consecutive surgical ICU patients with shock during the study period. After excluding patients who had not undergone surgery and those with missing data, 11,512 patients were selected, 4699 of whom had received hyperoncotic albumin within the first $48 \mathrm{~h}$ of ICU admission. Covariate matching yielded 3600 hyperoncotic albumin-exposed patients successfully matched with 3600 control patients (Fig. 1). The demographic and perioperative clinical characteristics of the two groups are depicted in Tables 1 and 2, before and after matching. Most were Caucasian, $62 \%$ of male gender, with mean age of $66 \pm 13$ years, with a preponderance of cardiac surgical patients.

Propensity score techniques successfully balanced the variables in the matched subset (Fig. 2). Only ASA physical status and hetastarch exposure remained slightly imbalanced between the matched cohorts, using our ASD threshold of 0.046. (ASD 0.07 and 0.13 , respectively). We therefore re-adjusted for these factors when comparing hyperoncotic albumin patients to their matched controls on the study outcomes.

Within the propensity-matched patients, $20.3 \%, 2.9 \%$, and $4.4 \%$ of hyperoncotic albumin-exposed patients experienced stages 1, 2, and 3 of acute kidney injury, as compared to 19.6\%, 2.5\%, and 3.0\% of control patients (Fig. 3). Patients exposed to hyperoncotic albumin were $10 \%$ more likely (OR $1.10,95 \% \mathrm{CI} 1.04,1.17)$ to have been assigned a more severe AKI classification than their matched controls $(P=0.002)$, after adjusting for the imbalanced co-variables (Table 3).

In contrast, no statistically significant differences were found for any of the secondary outcome measures. The estimated odds ratio for liver injury was 1.16 (98.3\% CI $0.85,1.58$ ) (hyperoncotic albumin versus control, $P=0.25$ ). Likewise, in-hospital mortality between hyperoncotic albumin exposed and non-exposed patients was not significantly different (OR 0.88, 95\% CI 0.64, 1.20) $(P=0.32)$ (Table 3).

The estimated median duration of ICU stay was $64 \mathrm{~h}$ [interquartile range 41 to 119 ] for albumin patients and $50 \mathrm{~h}$ [interquartile range 29 to 115] for controls (Table 3).

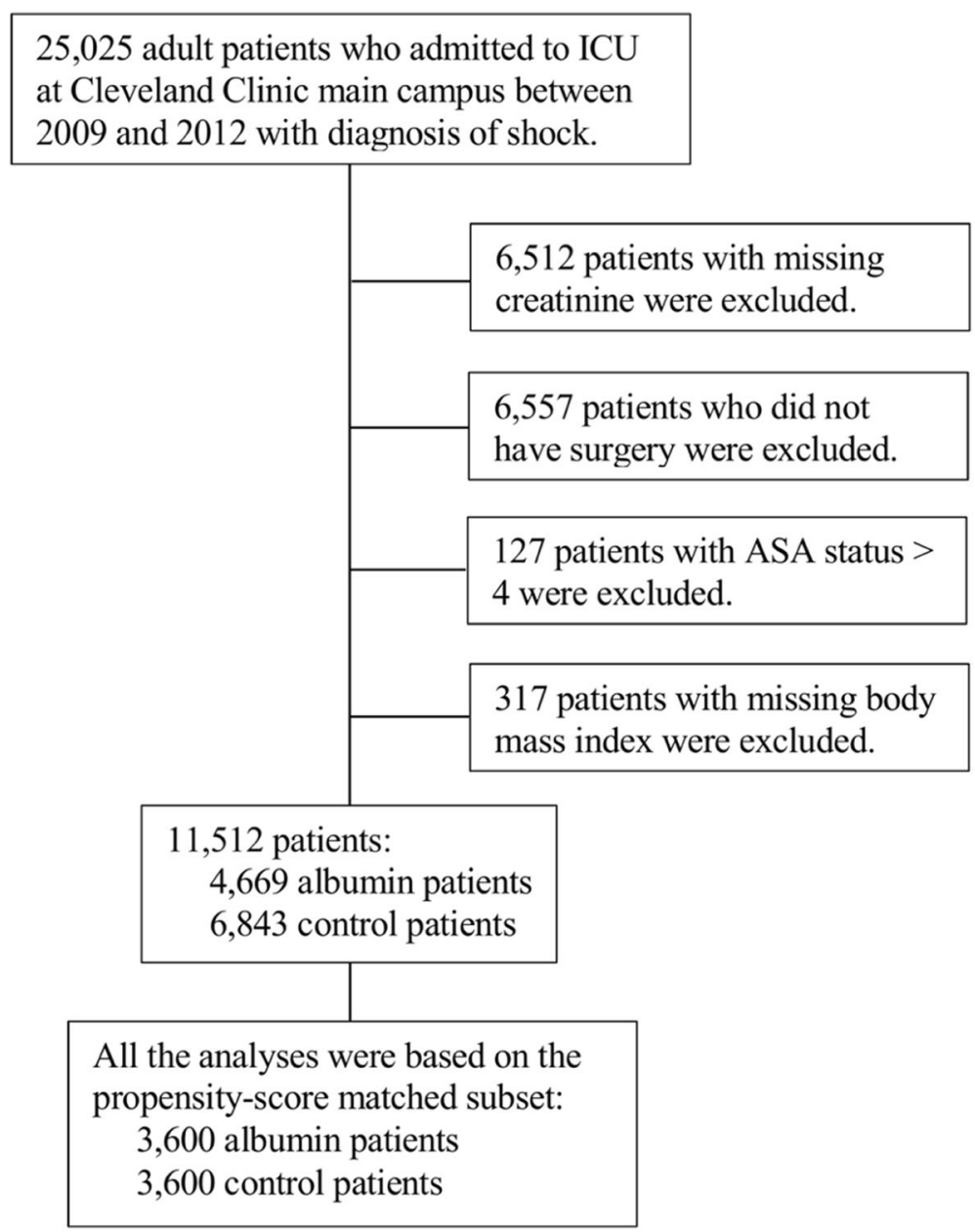

Fig. 1 Patient selection flow chart 


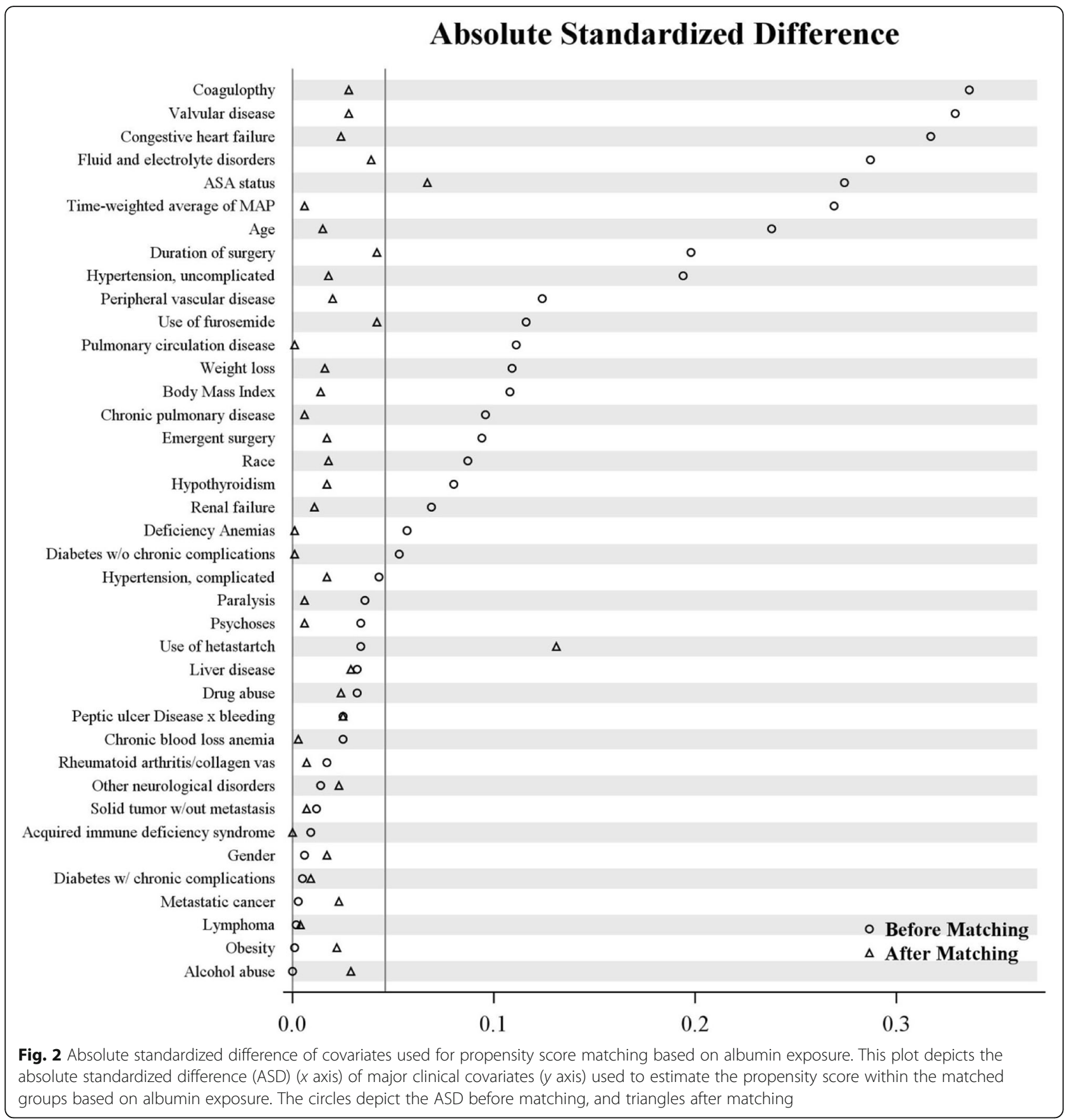

We did not observe any difference in length of ICU stay; log-rank test $P=0.02>$ the Bonferroni corrected significance criterion of 0.017 . The estimated hazard ratio for length of ICU stay was $1.05(98.3 \%$ CI $1.00,1.11)$ for hyperoncotic albumin vs. control patients, after adjusting for the imbalanced co-variables $(P=0.03)$ (Table 2). Discharges for patients who died in the ICU were considered as non-events and censored at the longest observed length of stay (Fig. 4).

\section{Discussion}

Our results suggest that early administration of 25\% albumin in postoperative shock may be associated with a more severe degree of AKI. Studies have indicated that development of AKI is associated with increased morbidity and mortality. For instance, $30-50 \%$ of septic patients develop AKI and in the sub-group that requires dialysis, 90-day mortality can be as high as $50 \%$ (Honore et al. 2015). Other investigators have previously challenged the 


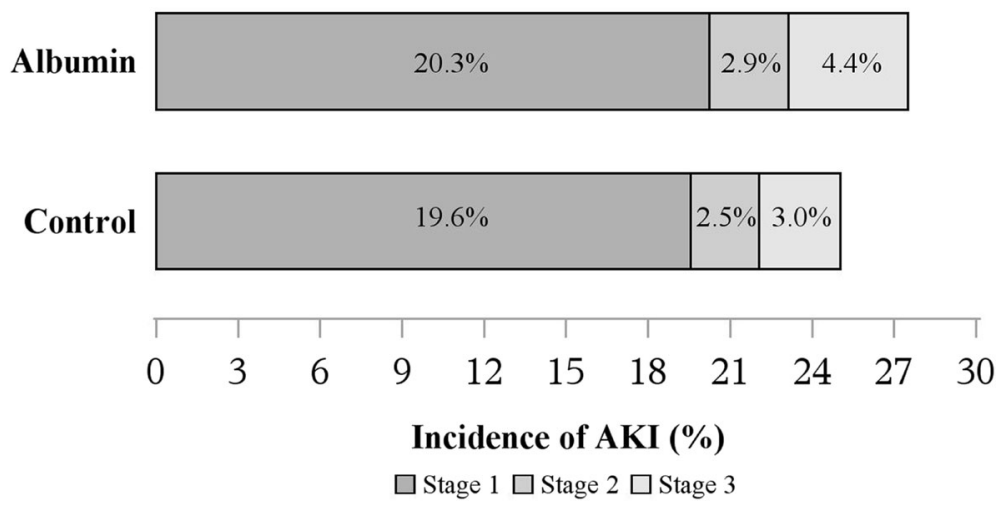

Fig. 3 Incidence of KDIGO stages 1-3 acute kidney injury for matched albumin and control patients

perception of benefit, and/or low risk, of hyperoncotic albumin in the critically ill (Schortgen et al. 2008; Geer et al. 1976; Goodwin et al. 1981; Grootendorst et al. 1988). Raghunathan et al. conducted a multi-center retrospective cohort analysis of over 60,000 medical patients with septic shock (Raghunathan et al. 2015). They found that co-administration of colloids (including albumin) with crystalloids during initial resuscitation was associated with increased costs and length of stay, yet without improved survival. Notably, after matching our subjects, significantly more patients had received hetastarches in the control group. While we adjusted for this difference in the analysis of outcomes, the increased incidence of AKI found in the albumin-exposed group of our study was contrary to what may be expected considering hetastarch exposure and supports our findings.

Earlier in 2008, Schortgen et al. reported an increased risk of AKI in the CRYCO study, a multicenter, prospective observational cohort study of patients with shock (Schortgen et al. 2008). They reported an overall incidence of a renal event of $17.4 \%$, defined as a 2 -fold increase in serum creatinine or need for dialysis. Among those exposed to hyperoncotic albumin, there was a significant risk of AKI [OR 5.99, 95\% CI 2.75-13.08] and ICU mortality [OR 2.79, 95\% CI 1.42-5.47]. Similar to our results, they found no increase in hepatic injury [OR 1.04, 95\% CI 0.58-1.89]. The smaller effect size notwithstanding, the increased risk of AKI identified in our study is concordant with the CRYCO study.

In contrast, the ALBIOS study of targeted albumin replacement in sepsis found neither nephrotoxicity nor mortality difference with albumin replacement (Caironi et al. 2014). This reinforces the concept of hypo-albuminemia as a consequence and not a cause of critical illness (Fleck et al. 1985; Hubner et al. 2016).

In 2016, Frenette et al. reported a 2-fold increased risk of AKI in cardiac surgery patients who received albumin (5\% and 25\%) (Frenette et al. 2014). Supporting a hypothesis of causation, they also found that the risk of AKI was dose-dependent. However, Lee et al. reported a 50\%

Table 3 Associations between hyperoncotic albumin exposure and outcomes among the propensity score matched patients

\begin{tabular}{|c|c|c|c|c|}
\hline Primary outcome & $\begin{array}{l}\text { Albumin } \\
N=3600\end{array}$ & $\begin{array}{l}\text { Control } \\
N=3600\end{array}$ & $\begin{array}{l}\text { Odds ratio }(95 \% \mathrm{Cl}) \\
\text { (albumin/control) }\end{array}$ & $P$ value \\
\hline Acute kidney injury & & & $1.10(1.04,1.17)$ & 0.002 \\
\hline No injury & $2610(72.5)$ & $2699(75.0)$ & & \\
\hline Stage 1 injury & $729(20.3)$ & 704 (19.6) & & \\
\hline Stage 2 injury & $104(2.9)$ & $90(2.5)$ & & \\
\hline Stage 3 injury & $157(4.4)$ & $107(3.0)$ & & \\
\hline Secondary outcomes & & & Odds ratio $(98.3 \% \mathrm{Cl})^{\dagger}$ & \\
\hline Liver injury & $137(3.8)$ & $118(3.3)$ & $1.16(0.85,1.58)$ & 0.25 \\
\hline \multirow[t]{2}{*}{ In-hospital mortality } & $114(3.2)$ & $127(3.5)$ & $0.88(0.64,1.20)$ & 0.32 \\
\hline & & & Hazard ratio $(98.3 \% \mathrm{Cl})^{+}$ & \\
\hline Length of ICU stay $^{\ddagger}$ (h) & $64[41,119]$ & $50[29,115]$ & $0.95(0.90,1.00)$ & 0.03 \\
\hline
\end{tabular}

${ }^{\dagger} P$ value $<0.017$ was considered significant (i.e., $0.05 / 3=0.017$, Bonferroni correction)

${ }^{\ddagger}$ Discharges for those patients who died in hospital were considered as non-events and censored at the longest observed length of stay 


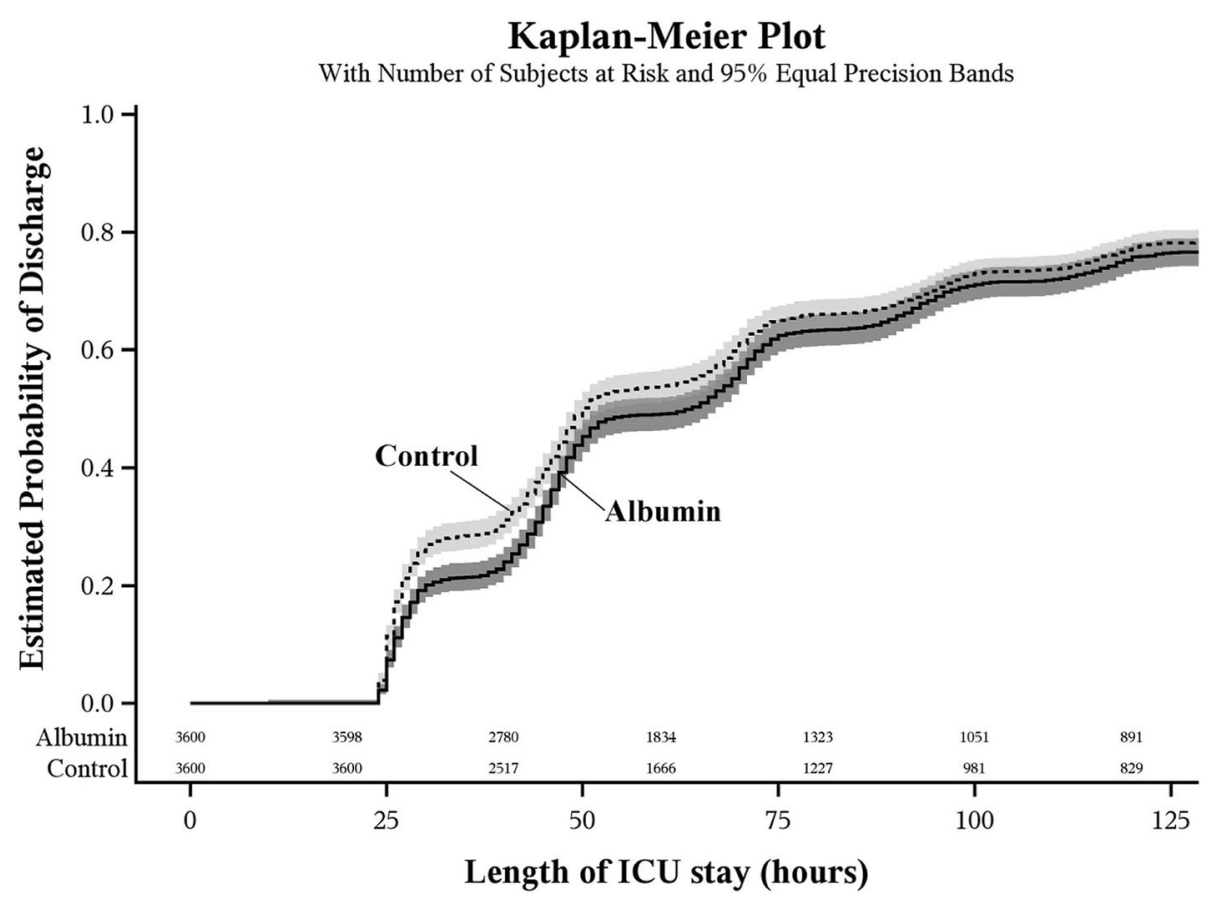

Fig. 4 Kaplan-Meier plot showing duration of ICU stay for propensity score matched albumin and control patients

decrease in AKI in cardiac surgery patients treated with $20 \%$ albumin preoperatively for serum albumin levels less than $4 \mathrm{~g} / \mathrm{dl}$ (Lee et al. 2016). Major surgery-like sepsis-is strongly associated with denudation of the endothelial glycocalyx (Steppan et al. 2011). Thus, Lee's study suggests that timing of administration, and the clinical context might modulate the effects of hyperoncotic albumin. Notably, their control group received albumin postoperatively (both arms eventually receiving similar total amounts), which may explain the magnitude of the observed effect. Ordinarily, cardiac surgery has a relatively high incidence of AKI, attributable to the perioperative physiologic perturbations from bleeding, cardiopulmonary bypass, and the associated systemic inflammatory response which could presage the occurrence of AKI (Bastin et al. 2013). Accordingly, the preponderance of cardiac surgical patients in our cohort, a post hoc finding, raises concern that early exposure to hyperoncotic albumin in such patients may exacerbate the risk, leading to a more severe stage of AKI.

It is not yet known what might explain such paradoxical harm from hyperoncotic albumin. Albumin is a structural component of the intact endothelial glycocalyx and is a plasma anti-oxidant (Becker et al. 2010). In vitro, albumin inhibits apoptosis of endothelial cells if the intercellular adhesions are intact (Leitch et al. 2013; Zoellner et al. 1996). Therefore, it has been postulated, but not yet clinically demonstrated, that albumin supplementation in shock may help restore the glycocalyx (Nicholson et al. 2000;
Leitch et al. 2013; Zoellner et al. 1996). Perhaps albumin administration prior to the onset of endothelial glycocalyx injury may be protective but further study is needed before recommending such preemptive resuscitation. However, as experience with other human blood products shows, the safety or beneficence of albumin cannot be assumed without question. Indeed, no two lots of human albumin solutions are identical, even from the same manufacturer. The solutions include molecules with a range of post-translational modifications that may attenuate their chelation or anti-oxidant capacity (Leitch et al. 2013). As such, any effects of albumin in shock are conditional on many as yet undetermined factors.

The pathophysiology of AKI after colloid exposure has been attributed to altered plasma oncotic forces and osmotic nephrosis described with hetastarches (Cittanova et al. 1996; Blasco et al. 2008; Schortgen et al. 2001). Basic research has proposed mechanisms that could promote renal injury as albumin filtered through glomeruli can promote renal interstitial inflammation, and dose-dependent increases in pro-inflammatory gene expression, TNF-alpha levels, and NF-kappa beta activity (Nicholson et al. 2000; Drumm et al. 2001a; Wheeler et al. 2011; Drumm et al. 2002; Drumm et al. 2001b; Gioannini et al. 2002; Kremer et al. 2011; Neuhaus et al. 2012). Another possible mechanism could be the adverse effect of albumin infusions on intracellular fluid volume demonstrated by Ernest et al. in both septic and postoperative cardiac surgery patients (Ernest et al. 1999; Ernest et al. 2001). They found that 
compared to saline, 5\% albumin increased extracellular fluid volume, expanding both the plasma and interstitial compartments beyond the infused volume; thus, leading to the inference that the extra volume was derived from the intracellular space. Extrapolating from this in the setting of shock-induced hyper-permeability with overall plasma volume loss, hyperoncotic albumin may indeed raise plasma volume but at the cost of further intracellular dehydration-potentially stressing an intracellular milieu already deranged by shock. Any benefit from plasma volume expansion may thus be countered by intracellular dehydration.

With respect to secondary outcomes, our investigation did not support association of hyperoncotic albumin with increased risk of liver injury, in-hospital mortality, or ICU length of stay. This was concordant with the study by Raghunathan et al., which found an inconsistent association between colloid exposure and mortality (Raghunathan et al. 2015). Our findings though differ from the CRYCO study, which showed a significant increase in risk of mortality associated with hyperoncotic albumin without risk of liver dysfunction after covariate adjustment (Schortgen et al. 2008).

The strengths of our study include evaluating effect of $25 \%$ albumin exposure early during the course of shock, addressing the period of greatest hemodynamic instability, and potential for renal injury. We leveraged a large highrisk patient population and electronic medical records of our institution. To limit bias and misclassification risk, we analyzed consecutive patients, identified using objective criteria. Also, diagnostic codes for the clinical covariates were applied by professionals blinded to the study. The analysis used propensity matching of covariates to limit differences in severity of illness among the patient samples. Moreover, we set a threshold for assessing imbalance after propensity score matching by using an absolute standardized difference of $<0.05$ between the groups. This is far stricter than the conventional threshold of 0.2 .

Our study has inherent limitations because it is a single center, retrospective study which limits generalizability. Although we matched for potential confounders, the role of other clinical factors, not retrievable from our institution's database, cannot be excluded as effect modifiers or confounders. We could not quantify the dose of $25 \%$ albumin, or characterize the type, and dose of crystalloids administered ( $0.9 \%$ saline or lactated Ringer's solution). This precluded assessment of dose-dependency with outcomes. This was also the case with hetastarches; however, our institutional protocols for hetastarches then, limited their use to no more than $1 \mathrm{~L}$ to avoid coagulopathy.

Confounding by indication can affect validity of retrospective, observational research of comparative effectiveness, and safety (Psaty and Siscovick 2010). To limit the risk of residual confounding, we adjusted for multiple factors, potentially associated with the primary outcome of AKI, and controlled for exposure to hetastarches.

Moreover, we note the concordance of our results with those of Raghunathan et al. (whose study specifically addressed confounding by indication by also using inverse probability weighting analyses for risk adjustment, yet found no benefit from the use of albumin). Furthermore, our approach using "big data" from an electronic medical record has been similarly used by other investigations to assess renal failure after kidney transplantation (Srinivas et al. 2017). These investigators showed that the use of large patient dataset significantly enhanced the predictive analytical models of graft function survival. Analysis of large datasets, may detect previously unsuspected risk factors for organ injury associated with established medications or management protocols.

The findings of this study are germane in supporting an association between hyperoncotic albumin exposure and AKI in early perioperative shock. Given the nephrotoxicity risks of hetastarches, the concordance of our findings with similar studies of resuscitation in shock supports a reexamination of the therapeutic indications of hyperoncotic albumin.

\section{Conclusions}

The use of hyperoncotic albumin for acute resuscitation in shock is controversial given its economic costs, absence of beneficial clinical outcomes relative to crystalloids, and the potential for nephrotoxicity. Our study suggests that exposure to hyperoncotic albumin during the first $48 \mathrm{~h}$ of perioperative shock may be associated with an increased risk of acute kidney injury, particularly among post-cardiac surgery patients. Within the matched groups, we did not detect differences in risk of liver injury, ICU length of stay or in-hospital mortality. Given the retrospective nature of the study, we view our findings as preliminary, and indicative of a need for prospective, randomized studies to achieve greater validity, and to identify the mechanisms for this apparent toxicity.

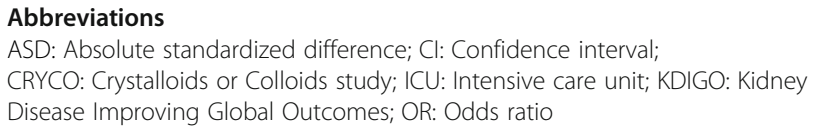

Acknowledgements

The authors thank Ms. Xiahong Li for her invaluable assistance with data collection and preparation.

\section{Funding}

This study was solely supported by institutional funds.

Availability of data and materials

The datasets used and/or analyzed during the current study are available from the corresponding author on reasonable request.

Authors' contributions

$\mathrm{CIU}$ contributed to the study conception and design, interpretation of data, drafting of the manuscript, and revising it for intellectual content. JY 
contributed to the statistical analysis, interpretation of the data, drafting of the manuscript, and revising it for intellectual content. MRW contributed to the study conception and design, interpretation of the data, drafting of the manuscript, and revising it for intellectual content. JD contributed to the study conception and design, data collection, analysis and interpretation of data, drafting of the manuscript, and revising it for intellectual content. BLU contributed to the study conception and design, interpretation of the data, drafting of the manuscript, and revising it for intellectual content. SD contributed to the study conception and design, interpretation of the data, drafting of the manuscript, and revising it for intellectual content. NR contributed to the study conception and design, interpretation of data, drafting of the manuscript, and revising it for intellectual content. JSH contributed to the study conception and design, data collection, analysis and interpretation of the data, drafting of the manuscript, and revising it for intellectual content. All authors read and approved the final manuscript.

\section{Ethics approval and consent to participate}

The Cleveland Clinic Institution Review Board approved this study and waived informed consent.

\section{Consent for publication}

Not applicable

\section{Competing interests}

The authors declare that they have no competing interests.

\section{Publisher's Note}

Springer Nature remains neutral with regard to jurisdictional claims in published maps and institutional affiliations.

\section{Author details}

${ }^{1}$ Center for Critical Medicine, Anesthesiology Institute, 9500 Euclid Avenue, (J4-331), Cleveland, OH 44195, USA. ²Department of Special Line Product Development, Progressive Insurance, 300 N. Commons Blvd, Cleveland, $\mathrm{OH}$ 44143, USA. ${ }^{3}$ Department of Inpatient Pharmacy, Cleveland Clinic Pharm D, 9500 Euclid Avenue, Cleveland, OH 44195, USA. ${ }^{4}$ Department of Quantitative Health Sciences, Lemer Research Institute, Cleveland Clinic, 9500 Euclid Avenue, Cleveland, OH 44195, USA. ${ }^{5}$ Quality and Patient Safety Institute, NI-CORE, Neurological Institute, 9500 Euclid Avenue, Cleveland, OH 44195, USA. ${ }^{6}$ Department of Nephrology, Glickman Urology and Kidney Institute, Cleveland Clinic, 9500 Euclid Avenue, Cleveland, OH 44195, USA. ${ }^{7}$ Critical Care Institute, Cleveland Clinic, P.O. Box 112412, Al Maryah Island, Abu Dhabi, United Arab Emirates.

\section{Received: 12 May 2018 Accepted: 20 November 2018}

Published online: 14 December 2018

\section{References}

Bastin AJ, Ostermann M, Slack AJ, Diller GP, Finney SJ, Evans TW. Acute kidney injury after cardiac surgery according to risk/injury/failure/loss/end-stage, acute kidney injury network, and kidney disease: improving global outcomes classifications. J Crit Care. 2013;28(4):389-96.

Becker BF, Chappell D, Jacob M. Endothelial glycocalyx and coronary vascular permeability: the fringe benefit. Basic Res Cardiol. 2010;105(6):687-701.

Blasco V, Leone M, Antonini F, Geissler A, Albanese J, Martin C. Comparison of the novel hydroxyethylstarch 130/0.4 and hydroxyethylstarch 200/0.6 in brain-dead donor resuscitation on renal function after transplantation. $\mathrm{Br}$ J Anaesth. 2008;100(4):504-8.

Brochard L, Abroug F, Brenner $M$, et al. An official ATS/ERS/ESICM/SCCM/SRLF statement: prevention and management of acute renal failure in the ICU patient: an international consensus conference in intensive care medicine. Am J Respir Crit Care Med. 2010;181(10):1128-55.

Bunn F, Trivedi D. Colloid solutions for fluid resuscitation. Cochrane Database Syst Rev. 2012;7:CD001319.

Caironi P, Tognoni G, Masson S, et al. Albumin replacement in patients with severe sepsis or septic shock. N Engl J Med. 2014;370(15):1412-21.

Chappell D, Jacob M, Hofmann-Kiefer K, Conzen P, Rehm M. A rational approach to perioperative fluid management. Anesthesiology. 2008;109(4):723-40.

Cittanova ML, Leblanc I, Legendre C, Mouquet C, Riou B, Coriat P. Effect of hydroxyethylstarch in brain-dead kidney donors on renal function in kidneytransplant recipients. Lancet. 1996;348(9042):1620-2.
Division of Biomedical Statistics and Informatics, Mayo Clinic (HSR CodeXchange). Computerized matching of cases to controls using the greedy matching algorithm with a fixed number of controls per case.Technical Report Series No. 56, [computer program]. Version 10/2003. Rochester: Division of Biomedical Statistics and Informatics, Mayo Clinic (HSR CodeXchange); 2003.

Drumm K, Bauer B, Freudinger R, Gekle M. Albumin induces NF-kappaB expression in human proximal tubule-derived cells (IHKE-1). Cell Physiol Biochem. 2002;12(4):187-96.

Drumm K, Gassner B, Silbernagl S, Gekle M. Inhibition of Na superset+/H superset+ exchange decreases albumin-induced NF-kappaB activation in renal proximal tubular cell lines (OK and LLC-PK1 cells). Eur J Med Res. 2001a;6(10):422-32.

Drumm K, Gassner B, Silbernagl S, Gekle M. Albumin in the mg/l-range activates NF-kappaB in renal proximal tubule-derived cell lines via tyrosine kinases and protein kinase C. Eur J Med Res. 2001b;6(6):247-58.

Elixhauser A, Steiner C, Harris DR, Coffey RM. Comorbidity measures for use with administrative data. Med Care. 1998;36(1):8-27.

Ernest D, Belzberg AS, Dodek PM. Distribution of normal saline and $5 \%$ albumin infusions in septic patients. Crit Care Med. 1999;27(1):46-50.

Ernest D, Belzberg AS, Dodek PM. Distribution of normal saline and 5\% albumin infusions in cardiac surgical patients. Crit Care Med. 2001;29(12):2299-302.

Finfer S, Bellomo R, Boyce N, et al. A comparison of albumin and saline for fluid resuscitation in the intensive care unit. N Engl J Med. 2004;350(22):2247-56.

Fleck A, Raines G, Hawker F, et al. Increased vascular permeability: a major cause of hypoalbuminaemia in disease and injury. Lancet. 1985;1(8432):781-4.

Frenette AJ, Bouchard J, Bernier P, et al. Albumin administration is associated with acute kidney injury in cardiac surgery: a propensity score analysis. Crit Care. 2014;18(6):602.

Geer RT, Soma LR, Barnes C, Leatherman JL, Marshall BE. Effects of albumin and/ or furosemide therapy on pulmonary edema induced by hydrochloric acid aspiration in rabbits. J Trauma. 1976;16(10):788-91.

Gioannini TL, Zhang D, Teghanemt A, Weiss JP. An essential role for albumin in the interaction of endotoxin with lipopolysaccharide-binding protein and sCD14 and resultant cell activation. J Biol Chem. 2002;277(49):47818-25.

Goodwin CW, Long JW 3rd, Mason AD Jr, Pruitt BA Jr. Paradoxical effect of hyperoncotic albumin in acutely burned children. J Trauma. 1981;21(1):63-5.

Grootendorst AF, van Wilgenburg MG, de Laat PH, van der Hoven B. Albumin abuse in intensive care medicine. Intensive Care Med. 1988;14(5):554-7.

Group. KDIGOKAKIW. KDIGO clinical practice guideline for acute kidney injury. Kidney Int Suppl. 2012;2(1):37-68.

Hartog CS, Kohl M, Reinhart K. A systematic review of third-generation hydroxyethyl starch (HES 130/0.4) in resuscitation: safety not adequately addressed. Anesth Analg. 2011;112(3):635-45.

Hiippala S, Linko K, Myllyla G, Lalla M, Makelainen A. Albumin, Hes-120 and Dextran-70 as adjuvants to red-blood-cell concentrates - a study on colloid osmotic-pressure changes in vitro. Acta Anaesth Scand. 1991;35(7):654-9.

Honore PM, Jacobs R, Hendrickx I, et al. Prevention and treatment of sepsisinduced acute kidney injury: an update. Ann Intensive Care. 2015;5(1):51.

Hubner M, Mantziari S, Demartines N, Pralong F, Coti-Bertrand P, Schafer M. Postoperative albumin drop is a marker for surgical stress and a predictor for clinical outcome: a pilot study. Gastroenterol Res Pract. 2016;2016:8743187.

Jiang $L$, Jiang S, Zhang M, Zheng Z, Ma Y. Albumin versus other fluids for fluid resuscitation in patients with sepsis: a meta-analysis. PLoS One. 2014;9(12): e114666.

Khwaja A. KDIGO clinical practice guidelines for acute kidney injury. Nephron Clin Pract. 2012;120(4):c179-84.

Kremer $\mathrm{H}$, Baron-Menguy $\mathrm{C}$, Tesse $\mathrm{A}$, et al. Human serum albumin improves endothelial dysfunction and survival during experimental endotoxemia: concentration-dependent properties. Crit Care Med. 2011;39(6):1414-22.

Lee EH, Kim WJ, Kim JY, et al. Effect of exogenous albumin on the incidence of postoperative acute kidney injury in patients undergoing off-pump coronary artery bypass surgery with a preoperative albumin level of less than $4.0 \mathrm{~g} / \mathrm{dl}$. Anesthesiology. 2016;124(5):1001-11.

Leitch A, Craig G, Sadler P. Human albumin solution resuscitation in severe Sepsis and septic shock. J Intensive Care Soc. 2013;14(1):45-52.

Levick JR, Michel CC. Microvascular fluid exchange and the revised Starling principle. Cardiovasc Res. 2010;87(2):198-210.

Moran M, Kapsner C. Acute renal failure associated with elevated plasma oncotic pressure. N Engl J Med. 1987;317(3):150-3.

Myburgh JA. The evidence for small-volume resuscitation with hyperoncotic albumin in critical illness. Crit Care. 2008;12(2):143. 
Neuhaus W, Schick MA, Bruno RR, et al. The effects of colloid solutions on renal proximal tubular cells in vitro. Anesth Analg. 2012;114(2):371-4.

Nicholson JP, Wolmarans MR, Park GR. The role of albumin in critical illness. Br J Anaesth. 2000:85(4):599-610.

Patel A, Laffan MA, Waheed U, Brett SJ. Randomised trials of human albumin for adults with sepsis: systematic review and meta-analysis with trial sequential analysis of all-cause mortality. BMJ. 2014;349:g4561.

Perel P, Roberts I, Ker K. Colloids versus crystalloids for fluid resuscitation in critically ill patients. Cochrane Database Syst Rev. 2013;2:CD000567.

Polito C, Martin GS. Albumin: physiologic and clinical effects on lung function. Minerva Anestesiol. 2013;79(10):1180-6.

Psaty BM, Siscovick DS. Minimizing bias due to confounding by indication in comparative effectiveness research: the importance of restriction. JAMA. 2010;304(8):897-8.

Raghunathan K, Bonavia A, Nathanson BH, et al. Association between initial fluid choice and subsequent in-hospital mortality during the resuscitation of adults with septic shock. Anesthesiology. 2015;123(6):1385-93.

Roch A, Guervilly C, Papazian L. Fluid management in acute lung injury and ards. Ann Intensive Care. 2011;1(1):16.

Schortgen F, Girou E, Deye N, Brochard L. Do hypooncotic fluids for shock increase the risk of late-onset acute respiratory distress syndrome? Intensive Care Med. 2010;36(10):1724-34.

Schortgen F, Girou E, Deye N, Brochard L, Group CS. The risk associated with hyperoncotic colloids in patients with shock. Intensive Care Med. 2008;34(12): 2157-68.

Schortgen F, Lacherade JC, Bruneel F, et al. Effects of hydroxyethylstarch and gelatin on renal function in severe sepsis: a multicentre randomised study. Lancet. 2001;357(9260):911-6.

Schuhlen H. Pre-specified vs. post-hoc subgroup analyses: are we wiser before or after a trial has been performed? Eur Heart J. 2014;35(31):2055-7.

Shankar-Hari M, Phillips GS, Levy ML, et al. Developing a new definition and assessing new clinical criteria for septic shock for the third international consensus definitions for Sepsis and septic shock (Sepsis-3). Jama-J Am Med Assoc. 2016;315(8):775-87.

Srinivas TR, Taber DJ, Su Z, et al. Big data, predictive analytics, and quality improvement in kidney transplantation: a proof of concept. Am J Transplant. 2017;17(3):671-81.

Steppan J, Hofer S, Funke B, et al. Sepsis and major abdominal surgery lead to flaking of the endothelial glycocalix. J Surg Res. 2011;165(1):136-41.

Stockwell MA, Scott A, Day A, Riley B, Soni N. Colloid solutions in the critically ill. $A$ randomised comparison of albumin and polygeline 2. Serum albumin concentration and incidences of pulmonary oedema and acute renal failure. Anaesthesia. 1992b;47(1):7-9.

Stockwell MA, Soni N, Riley B. Colloid solutions in the critically ill. A randomised comparison of albumin and polygeline. 1. Outcome and duration of stay in the intensive care unit. Anaesthesia. 1992a;47(1):3-6.

Tonnessen T, Tollofsrud S, Kongsgaard UE, Noddeland H. Colloid osmoticpressure of plasma replacement fluids. Acta Anaesth Scand. 1993;37(4):424-6.

Vincent JL, Moreno R, Takala J, et al. The SOFA (sepsis-related organ failure assessment) score to describe organ dysfunction/failure. Intensive Care Med. 1996;22(7):707-10.

Wheeler DS, Giuliano JS Jr, Lahni PM, Denenberg A, Wong HR, Zingarelli B. The immunomodulatory effects of albumin in vitro and in vivo. Adv Pharmacol Sci. 2011;2011:691928.

Woodcock TE, Woodcock TM. Revised Starling equation and the glycocalyx model of transvascular fluid exchange: an improved paradigm for prescribing intravenous fluid therapy. Br J Anaesth. 2012;108(3):384-94.

Zarychanski R, Abou-Setta AM, Turgeon AF, et al. Association of hydroxyethyl starch administration with mortality and acute kidney injury in critically ill patients requiring volume resuscitation: a systematic review and metaanalysis. JAMA. 2013;309(7):678-88.

Zoellner $H$, Hofler M, Beckmann $R$, et al. Serum albumin is a specific inhibitor of apoptosis in human endothelial cells. J Cell Sci. 1996;109(Pt 10):2571-80.

Ready to submit your research? Choose BMC and benefit from:

- fast, convenient online submission

- thorough peer review by experienced researchers in your field

- rapid publication on acceptance

- support for research data, including large and complex data types

- gold Open Access which fosters wider collaboration and increased citations

- maximum visibility for your research: over $100 \mathrm{M}$ website views per year

At BMC, research is always in progress.

Learn more biomedcentral.com/submissions 